\title{
ESCOLA INCLUSIVA: UM NOVO OLHAR PARA O CURRÍCULO DE UMA ESCOLA PARA TODOS ${ }^{1}$
}

\author{
INCLUSIVE SCHOOL: A NEW LOOK AT A CURRICULUM SCHOOL FOR \\ EVERYONE
}

\section{ESCUELA INCLUSIVA: UNA NUEVA MIRADA PARA UNA ESCUELA DE CURRICULUM PARA TODOS}

\author{
Eladio Sebastián Heredero \\ UAH / Universidad de Alcalá de Henares - Espanha \\ E-mail: eladio.sebastian@gmail.com
}

\begin{abstract}
RESUMO
Este trabalho tem como objetivo organizar alguns elementos para o debate educacional em torno do currículo da escola do século XXI, que faz parte do modelo de inclusão escolar para todos. Organizamos o discurso a partir do modelo de sociedade intercultural e heterogênea sobre o que entendemos pela qualidade da educação e a necessidade de estabelecer uma mudança ou, como chamamos, uma reconstrução do modelo de escola, sua gestão e seu currículo a partir de objetivos compartilhados. Centramos o tema sobre três elementos chave do currículo, como são os conteúdos, sua organização e finalidade em uma sociedade em mudança e com alunos digitais, com conteúdos informais e formais e a necessidade de abordar as competências tanto cognitivas como não cognitivas que permitam a sua incorporação na sociedade; para posteriormente, abordar a importância da mudança de metodologias como forma de pôr em prática o paradigma construtivista, centrando toda a ação no aluno e deixando o protagonismo de mediação ao professor. Por fim, terminamos com algumas reflexões sobre avaliação, seu significado e sua função atual.
\end{abstract}

Palavras-chave: Currículo, Inclusão, Organização escolar.

\begin{abstract}
This work aims to organize certain elements of the educational debate on the school curriculum of the XXI century is part of the model of inclusive school for all. We have organized the issue based on the model of intercultural and diverse society what we would understand by quality in education and the need for a change or, as we call it, a reconstruction of the school model, its management and its curriculum from shared objectives. We focus the issue on three key elements of the curriculum such as content, organization and purpose in a changing society and a digital students with informal and formal content and the need to address both cognitive and non-cognitive skills that allow them to join society; to further address the importance of change in methodologies as a way to implement the constructivist paradigm focusing the action on
\end{abstract}

\footnotetext{
${ }^{1}$ Tradução de Daiane Natalia Schiavon, doutora em Educação pela UNESP/FCLAr.
} 
the student and leaving the mediation role of the teacher and end with some thoughts on assessing its meaning and its current role.

Key words: curriculum, inclusive school, school organitation.

\section{RESUMEN}

Este trabajo pretende organizar algunos elementos para el debate educativo en torno al currículo de la escuela del siglo XXI que se enmarca dentro del modelo de escuela inclusiva para todos y todas. Hemos organizado el discurso partiendo del modelo de sociedad intercultural y heterogénea sobre lo que entenderíamos por calidad en educación y la necesidad de establecer un cambio o, como nosotros llamamos, una reconstrucción del modelo de escuela, de su gestión y de su currículo a partir de unos objetivos compartidos. Centramos el tema sobre tres elementos clave del currículo como son los contenidos, su organización y finalidad en una sociedad cambiante y con unos alumnos digitales, con contenidos informales y formales y la necesidad de abordar las competencias tanto cognitivas como no cognitivas que le permitan incorporarse a la sociedad; para posteriormente abordar la importancia de cambio en metodologías como forma de poner en práctica el paradigma constructivista centrando toda la acción en el alumno y dejando el protagonismo de mediación al profesor y finalizamos con unas reflexiones sobre la evaluación su significado y su función actual.

Palabras clave: Currículo, Inclusión, Organización escolar.

\section{INTRODUÇÃO}

Estamos na segunda década do século XXI e, todavia falando de escola inclusiva, me surge a dúvida de que se, estamos trabalhando na direção correta ou estamos deslumbrados por uma ideia que, por si mesma, pode ser excludente. A sociedade de hoje é mais diversa, intercultural e mais heterogênea do que nunca, e a escola, como subsistema, é igual. Portanto, falar sobre a escola inclusiva que há em alguns centros educativos, pode ser uma contradição se não for entendida como uma escola para todos, porque esta é a escola que nós temos, esta é a escola do século XXI que temos que conviver; isto é, não é simplesmente incluindo pessoas com deficiência minorias ou de identidade sexual diferente, que inclui muitas outras diferenças - que fazem que uma sala de aula tenha tantas singularidades como alunos.

Neste contexto, o que fazer? Sou da opinião, junto com muitos outros pensadores sobre a ideia de refundar a escola, o que significa repensar a escola que temos e a escola que desejamos dentro dela. E isso desde os planejamentos macro, como programas e projetos da escola, considerando-a como uma entidade com autonomia que a legislação dá, até o nível micro, como os trabalhos com os alunos através de metodologias inovadoras e variadas, para o desenvolvimento de um currículo 
inclusivo. A escola do século XXI tem a necessidade de mudar os modelos deste século que a dominam.

Nesse sentido, Fullan (2002) afirma que seria necessário, administradores e gestores da educação discutirem que é preciso conceituar a maneira de mudar o sistema atual de forma profunda e específica. Permito-me acrescentar que, os gestores das escolas façam que isso aconteça promovendo mudanças desde dentro, sob a concepção de instituições que aprendem.

Inclusão e qualidade caminham juntas, porque ambas estão dentro dos objetivos, tanto dos sistemas educacionais quanto de suas instituições; da mesma maneira que a inclusão escolar está ligada à reorganização do que ensinar e de como ensinar, desde as abordagens construtivistas da aprendizagem.

\section{Desenvolvimento: Abrindo o diálogo}

Começaremos esta reflexão com aquilo que entendemos por qualidade na educação, uma vez que a escola em que trabalhamos apresenta a configuração que tem e os alunos que tem, portanto teremos que saber o que é qualidade, para procurá-la, modificando o que funciona incorretamente $\mathrm{e}$ melhorando $\mathrm{o}$ que funciona adequadamente.

Há diferentes definições daquilo que é qualidade, que depende do momento e autor, dão um sentido ou outro a esse termo, na verdade, poderíamos considerar que, a princípio, é um termo ambíguo. No entanto, Barrett et al. (2006), após uma análise profunda e exaustiva de relatórios de grande prestígio a nível internacional em torno da qualidade educativa, apresenta cinco dimensões do termo:

- Eficácia,

- Eficiência,

- Equidade

- Relevância

- Sustentabilidade.

Devemos pensar que esses cinco fatores podem ser usados para analisar a qualidade dos processos de mudança planejados, visando a sua melhoria. Portanto, uma escola que se preze, deve analisar essas dimensões e trabalhar para seu desenvolvimento. E, como observamos, a equidade está dentro delas, o que necessariamente nos leva ao núcleo da questão: escola de qualidade é inclusiva e seu currículo serve para a aprendizagem de todos, "[...] a responsabilidade não é suficiente, 
HEREDERO, E. S.

não basta apenas garantir o acesso; é necessário garantir a permanência deles e a qualidade do ensino, possibilitando o crescimento desses indivíduos" (SEBASTIAN HEREDERO, 2010, p.196).

\section{A segunda questão a ser discutida é a gestão de escolas inclusivas}

Abordamos agora a conceituação sobre qualidade, e temos visto como fatores de mesma eficiência e eficácia. Ao falar sobre gestão em termos gerais, esses dois fatores estão aí. Mas a escola atual é eficaz e eficiente? Pensemos em algumas das práticas que vemos nelas e reflitamos: deixar os grupos mais complicados para o último chega? A liderança dirigida existe? ou, como é o trabalho do professor dentro da escola?. López (1994) indicou sete indicadores do que seria uma gestão de qualidade: Direçãoliderança; Recursos humanos: seleção, formação, reconhecimento/recompensas e plano de carreira; Participação; Autonomia; Orientação; Impacto na sociedade; Resultados.

Vamos analisar, a partir desses indicadores, como é a gestão de nossos centros educativos e o que poderia ser melhorado. Claro que por isso devemos, também, pensar sobre a comunidade escolar e sua participação. Não cabe hoje em dia deixar de lado as famílias neste processo. E dentro desta reflexão preliminar, trabalhar todas as instâncias da comunidade educativa na escola que queremos e fazê-los participar do currículo e de seu desenvolvimento, incluindo a avaliação. E, assim, abrir a escola como espaço corresponsável da educação dos mais jovens.

\section{Uma Escola que aprende}

Pode-se afirmar que a qualidade está associada ao termo melhoria, entendida como a incorporação de "[...] respostas mais aceitáveis do que as existentes a respeito dos valores ou prioridades estabelecidos". (GAIRÍN, 2009, p. 22). Bem, na busca desse tipo de respostas melhores que as que se tem é para onde tem que se trabalhar por toda a equipe docente, desde uma perspectiva de trabalho em equipe, colaborativa até os objetivos em comum.

Parece mentira que até hoje em alguns dos projetos educativos haja uma dissonância tão grande entre a teoria e a prática, que em algumas escolas se planejem por escrito os objetivos e depois estes são esquecidos na realidade do dia a dia. Buscar o compromisso com a educação deve ser o objetivo das comunidades educativas, mas, esse objetivo deve ser planejado de forma responsável e participativa, e acima de tudo 
assumida. As escolas que realmente querem crescer e mudar, a primeira coisa que assumem são objetivos comuns de compromisso pela educação de todos.

E para que uma escola aprenda, seus protagonistas devem aprender e neste caso, os que também necessitam são os próprios professores, tanto em aspectos de organização e gestão da sala de aula, como aqueles relacionados às suas práticas educativas.

Um currículo por si só não vale a pena, isto está comprovado. É a implementação do mesmo que o torna diferente. Promover a formação dos professores é um dos pilares básicos desta nova perspectiva escolar. E propomos como elemento de reflexão a forma de fazer isso, ou seja, como é a formação de uma escola que aprende? Devemos concordar que é uma auto formação no próprio seio da escola onde isso aparece: em um contexto de ensino entre iguais sobre o mesmo ou similares problemas; em práticas de ensino bem sucedidas com grupos de alunos de mesmas características; sobre metodologias que são ativas e praticadas na própria escola, onde o objetivo é que todos aprendam.

O diálogo constante, os espaços de coordenação formal ou informal e os momentos de reflexão e formação, devem ser uma característica que, por certo, se junta à gestão e é capaz de organizar isto dentro das propostas de como ensinamos a partir, daqueles objetivos compartilhados de educar a todos com qualidade.

Há um autor que sigo há alguns anos e que diz que a escola deve ser um espaço de felicidade, Schank (2013), que me fez refletir sobre o que acontece na escola e sua dinâmica, partindo da base que, para muitas crianças do século que vivemos, ativas, auto didatas e digitais, a escola é chata e eles não querem aprender nela. Esse fato faz que em contextos em que os alunos são estimulados a descobrir, conhecer, experiênciar, etc, aprendem de outra forma, e assim, a escola torna-se um espaço agradável em que eles querem compartilhar suas experiências, produzindo a aprendizagem.

\section{O Currículo Inclusivo}

Tedesco (2011, p.37) diz sobre a educação para o século XXI: "As respostas educacionais devem ser elaboradas no marco de um projeto da sociedade "e é confirmada por fatos como a importância, como em países como Finlândia ou Coréia, que se dá a educação por parte da sociedade e sua correlação com resultados em avaliações internacionais”. Em todos esses países, os currículos são semelhantes e, 
HEREDERO, E. S.

independentemente dos elementos que incluem, fazem questão, ademais, de que o valor da educação como projeto da sociedade esteja sempre acima.

Sem dúvida, devemos mudar e inovar para combater o fracasso. Não vale a pena culpar os alunos de não estudar, porque não o farão se não lhes damos algo que seja atrativo para eles. Talvez o planejamento de um currículo inclusivo comece por oferecer algo que é útil para eles e aplicável no seu dia a dia e de fato está esta sendo trabalhado isso: são as chamadas competências básicas. Defino este termo como o que permanece em um aluno depois que ele estudou; o que significa recombinar tudo o que ele aprendeu para que lhe sirva de algo no seu dia a dia. As teorias construtivistas do aprendizado nos falam de aprendizagens significativas e é disso que se trata, de que aquilo que aprendem seja útil, que sejam capazes de aplica-lo e usá-lo. Só assim conseguiremos a verdadeira aprendizagem.

Claro que temos um desafio adicional, é o como ensinar, parte fundamental do currículo e para o qual já me referi, mas sobre o que quero insistir. O currículo verdadeiro para o século XXI, e mais, se pretende alcançar a todos, deve centrar seus investimentos na metodologia de ensino: até quando teremos que esperar para ver que essas práticas passadas não funcionam?

Parece claro que a educação enfrenta um grande desafio na inclusão da diversidade e, de acordo com o relatório da OCDE (2010), esse problema afeta especialmente aos professores, o que leva, por um lado, à necessidade de repensar e reformular sua formação inicial e, por outro lado, as estratégias de desenvolvimento profissional, a fim de poder incorporar as habilidades de ensino a crianças de contextos diferentes. O uso de recursos tecnológicos de todos os tipos, internet na sala de aula, manipulação e pesquisa, o trabalho ativo do aluno e a mediação do professor como tarefa principal estão na base da mudança. Não pretendo insistir, mas uma escola que realmente quer manter-se atualizada, ser inovadora e de ponta deve trabalhar de forma colaborativa entre todos os profissionais nesta direção.

E agora vamos aos conteúdos, talvez um dos elementos mais discutidos e debatidos e de que mais polêmica gera. A primeira das perguntas é definir se concordamos com o que pretendemos em cada etapa educativa. Na educação infantil, concordamos que queremos um desenvolvimento da criança em seus aspectos comunicativos, relacionais, afetivos e de autonomia, obviamente nos níveis de que 
estamos falando. Para a primeira parte da educação básica ou fundamental ${ }^{2}$ durante 2 ou 3 anos escolares, queremos alcançar a alfabetização linguística e matemática dos meninos e meninas. No final da etapa básica, com cerca de 5 ou 6 anos de escolarização, concordamos que o fundamental para o alunado, é o uso desta alfabetização para aprender, ou seja, o domínio das áreas instrumentais e a partir daí, como objetivo final da educação básica e fundamental, quando completarem os 8,9 ou 10 anos de escolarização básica ou fundamental, para adquirir os conhecimentos fundamentais que lhe permitam a incorporação na sociedade ou que siga em outras etapas educativas.

Bem, se concordarmos com isso, teremos de concordar que em um primeiro momento, isto é, até o $5^{\circ}$ ou $6^{\circ}$ ano do ensino fundamental não importa o conteúdo que lhes damos, o que, aliás, se analisarmos, qualquer currículo os verão várias vezes ao longo de sua escolaridade, o que é realmente importante é que esses conteúdos que aparecem nas suas lições, textos, trabalhos, etc. sejam o instrumento para se desenvolver bem a compreensão dos mesmos, seu relacionamento com outras aprendizagens, sua aplicação, porquê a entender, e todas as habilidades do pensamento, que Bloom (1979) já descreveu, em que o conteúdo não é o fim do instrumento. Somente a partir deste momento é quando adquire a relevância transcendental dos conteúdos ${ }^{3}$ e é onde eles serão a base para a aprendizagem futura.

Mas, minha pergunta é: para que serve dar muito conteúdo ao alunado? Pensando na indicação anterior de significado e aplicabilidade, se for incapaz de compreendê-los, interpretá-los ou recombiná-los, porque não tem a estrutura mental anterior alcançada por uma boa alfabetização e um trabalho eficiente no uso desses instrumentos para aprender, buscar informações, para entender.

Bem, mesmo que pareça mentira isso é o que é feito em algumas escolas e o que é realmente importante, que é aprender a aprender, é deixado de lado.

\footnotetext{
${ }^{2}$ Partimos da base que a maioria dos sistemas educativos inicia essa etapa escolar em torno dos 6 anos de idade e que tem uma duração nos países desenvolvidos de cerca de 9 ou 10 anos de duração, obrigatório e gratuito.

${ }^{3}$ Isso não significa negar a importância do conteúdo nos primeiros cursos da educação obrigatória, o que se trata de ressaltar o que não se deveria centrar todo o processo educativo nos resultados medidos por eles e sim no que os alunos fazem, entendem e deles.
} 
HEREDERO, E. S.

Pensemos que em nossas escolas de hoje, na vida dos alunos, nem todos aprendem as mesmas coisas, uma vez que cada um tem distintas capacidades, sendo a aprendizagem informal tão forte quanto à aprendizagem formal, da mesma forma que nem todos devem estar fazendo as mesmas coisas ao mesmo tempo.

Se, como mencionado anteriormente, todos aprendem de todos e com todos, a escola deve ser o espaço onde isso acontece, enquanto acomoda a outras maneiras de aprender a incorporação da bagagem pessoal de nossos alunos e sua criatividade a partir dos planejamentos para buscar o sucesso escolar dos mesmos.

Por outro lado, pensando no que é necessário para um cidadão do século XXI com as grandes mudanças que ocorrem no conhecimento e no desenvolvimento, e partindo de que todo sistema educacional tem três grandes objetivos - a saber: dar forma à identidade do aluno, integrar conhecimento e ética e prepará-lo para sua incorporação ativa na sociedade - é necessário que o currículo inclusivo incorpore competências cognitivas e competências não cognitivas.

As competências não cognitivas envolvem: criatividade, autonomia, espírito crítico, cidadania, e são cada vez mais necessárias para a realização pessoal e construção como pessoa; mas, além disso, elas são as mais exigidas por empresas na seleção de seus candidatos; o que torna transcendental essa incorporação no que ensinar nas escolas.

E, dentro desta revisão sobre o currículo de uma escola para todos, ainda quero incorporar alguns pensamentos para o debate sobre a avaliação, partindo do princípio irrefutável de que a avaliação apenas se fundamenta se é feita para promover a mudança.

Bem a partir daqui, a primeira coisa que eu me atrevo a afirmar é que a repetição do ano letivo é inútil. As investigações mais prestigiadas neste campo assim indicam; da mesma forma que indicam o porquê, e a razão está em que eles recebem mais do mesmo, algo que os estudantes rejeitaram e isso se manifestou como ineficiente. Mas os resultados não são iguais quando mudam as metodologias, os materiais e até mesmo a organização de conteúdo.

Mediante uma avaliação negativa concordamos que sempre afirmamos que é aluno que não aprendeu, mas a verdade é que não podemos afirmar categoricamente, porque existem muitos fatores que podem ter levado a este resultado negativo, desde os derivados da forma de avaliação, a maneira de perguntar, a análise de respostas, [...] ou mesmo para o humor ou o físico do que responde. 
Por isso, diante dos resultados de qualquer processo de avaliação, devemos pensar sobre o que fazer a partir deles e propor mudanças ou melhorias na função dos mesmos. Por sinal, e dependendo da ideia anteriormente exposta, uma avaliação não é responder a uma prova escrita ou a dez, é um processo reflexivo sobre como vão nossos alunos em seu processo educativo. O professor deve conhecer como eles estão aprendendo através dos registros de observação de produções, atividades e condutas sobre os conteúdos abordados.

Nada de novo com o que foi exposto até agora, apenas alguns pontos para o debate e discussão. Fazer que realmente exista autonomia nas escolas seria o objetivo final e a novidade, para tornar nossos centros educacionais capazes de organizar seus currículos, de acordo com os alunos que tenham e pensando sobre o que é primordial e necessário, além de organizar os recursos materiais e pessoais disponíveis para esse fim.

\section{A modo de (in) conclusão}

Vamos refletir, então, e discutir em nossas escolas como seria a melhor maneira de repensar o currículo, de organizá-lo de uma maneira que seja eficiente.

Esta não é uma tarefa fácil, deve ser feita gradualmente e em consenso, refletindo sobre cada decisão em um trabalho em equipe que nem todos irão aderir, mas que segundo veem os frutos os abraçarão.

Pensemos em como organizar as disciplinas, sempre como resultado de controvérsias, porque cada um acredita que o seu é o mais importante, com todas as lições já aprendidas sobre interdisciplinaridade e sobre o conceito de área de conhecimento, muito mais próximo das tendências mundiais comentadas do desenvolvimento das competências-chave nos sujeitos na fase de aprendizagem.

Levemos em prática nossas próprias metodologias por recombinação das existentes e testadas em nosso próprio contexto, que levam o aluno a ser o protagonista de seu próprio desenvolvimento e de seu próprio aprendizado, o professor como mediador que procura desenvolver a competência de aprender a aprender, modificando o que é necessário após um processo reflexivo de avaliação de sua prática docente dos resultados do processo de ensino do processo de ensino e aprendizagem.

Vamos discutir o que é uma escola que aprende e queremos aprender desde a perspectiva dos objetivos acordados e compartilhados em que o fundamental é construir uma escola que se adapte aos alunos e não o contrário. 


\section{REFERÊNCIAS}

BARRETT, A. M. et al. The concept of quality in education: a review of the "international" literature on the concept of quality in education. Bristol: University of Bristol, 2006.

BLOOM, B. Taxonomía de los objetivos de la educación. Buenos Aires: El Ateneo, 1979.

FULLAN, M. Los nuevos significados del cambio en educación. Barcelona: Octaedro, 2002.

GAIRÍN, J. Cambio y mejora: la innovación en el aula, equipo de profesores y centro. In: PAREDES, J.; HERRÁN, A. de la. (Coord.). La práctica de la innovación educativa. Madrid: Síntesis, 2009. p. 21-48.

LÓPEZ, F. La gestión de la calidad en educación. Madrid: La Muralla, 1994.

OCDE - ORGANIZAÇÃO PARA A COOPERAÇÃO E DESENVOLVIMENTO ECONÓMICO. Educating teachers for diversity: meeting the Challenge. Paris: OCDE, 2010

SCHANG, R. Enseñando a pensar. Madrid: Erasmus Ediciones, 2013.

SEBASTIAN HEREDERO, E. A escola inclusiva e estratégias para fazer frente a ela: as adaptações curriculares. In Acta Scientiarum, [S.1.], v.32, n.2, p.193208, 2010. Disponible en: <http://periodicos.uem.br/ojs/index.php/ActaSciEduc/ article/view/9772/9772>. Acceso em: 26 out. 2017.

TEDESCO, J.C. Los desafíos de la educación del siglo XXI. In Revista Iberoamericanade Educación, [S.1.], n.55, p.31-47, 2011. Disponible en: <http://www.rieoei.org/rie55a01.pdf>. Acceso en: 26 out. 2017. 